\title{
Conversion of $\alpha$-linolenic acid to eicosapentaenoic, docosapentaenoic and docosahexaenoic acids in young women
}

\author{
Graham C. Burdge* and Stephen A. Wootton \\ Institute of Human Nutrition, University of Southampton, Southampton, UK \\ (Received 5 October 2001 - Revised 30 May 2002 - Accepted 19 June 2002)
}

\begin{abstract}
The extent to which women of reproductive age are able to convert the $n-3$ fatty acid $\alpha$-linolenic acid (ALNA) to eicosapentaenoic acid (EPA), docosapentaenoic acid (DPA) and docosahexaenoic acid (DHA) was investigated in vivo by measuring the concentrations of labelled fatty acids in plasma for $21 \mathrm{~d}$ following the ingestion of $\left[U_{-}{ }^{13} \mathrm{C}\right]$ ALNA $(700 \mathrm{mg}) .\left[{ }^{13} \mathrm{C}\right]$ ALNA excursion was greatest in cholesteryl ester (CE) (224 (SEM 70) $\mu \mathrm{mol} / \mathrm{l}$ over $21 \mathrm{~d}$ ) compared with triacylglycerol (9-fold), non-esterified fatty acids (37-fold) and phosphatidylcholine (PC, 7-fold). EPA excursion was similar in both PC (42 (SEM 8) $\mu \mathrm{mol} / \mathrm{l})$ and CE (42 (SEM 9) $\mu \mathrm{mol} / \mathrm{l})$ over $21 \mathrm{~d}$. In contrast both $\left[{ }^{13} \mathrm{C}\right] \mathrm{DPA}$ and $\left[{ }^{13} \mathrm{C}\right] \mathrm{DHA}$ were detected predominately in PC (18 (SEM 4) and 27 (SEM 7) $\mu \mathrm{mol} / 1$ over $21 \mathrm{~d}$, respectively). Estimated net fractional ALNA inter-conversion was EPA $21 \%$, DPA $6 \%$ and DHA $9 \%$. Approximately $22 \%$ of administered $\left[{ }^{13} \mathrm{C}\right]$ ALNA was recovered as ${ }^{13} \mathrm{CO}_{2}$ on breath over the first $24 \mathrm{~h}$ of the study. These results suggest differential partitioning of ALNA, EPA and DHA between plasma lipid classes, which may facilitate targeting of individual $n-3$ fatty acids to specific tissues. Comparison with previous studies suggests that women may possess a greater capacity for ALNA conversion than men. Such metabolic capacity may be important for meeting the demands of the fetus and neonate for DHA during pregnancy and lactation. Differences in DHA status between women both in the nonpregnant state and in pregnancy may reflect variations in metabolic capacity for DHA synthesis.
\end{abstract}

Women: $\alpha$-Linolenic acid: Stable isotopes: Docosahexaenoic acid: Plasma

n-3 Long-chain polyunsaturated fatty acids (LCPUFA), principally docosahexaenoic acid (22:6n-3; DHA), are important structural components of cell membranes. Maintenance of appropriate levels of $n-3$ LCPUFA in membrane phospholipids is important for ensuring cell function. Alterations to the eicosapentaenoic acid (20:5n-3; EPA) and DHA content of membrane phospholipids relative to other fatty acids, in particular those of the n-6 series, may modify cell function (Innis, 1991; Calder, 1999). However, $\alpha$-linolenic acid (18:3n-3; ALNA), the putative precursor of EPA and DHA, is the principal dietary $n-3$ fatty acid in individuals consuming a Western diet (about $1.5 \mathrm{~g} / \mathrm{d}$ ). Since estimated intakes of ALNA are 25-fold and 15-fold greater than EPA and DHA, respectively (Ministry of Agriculture, Fisheries and Food, 1997), the metabolic capacity of an individual for ALNA conversion and for mobilisation of its longer-chain metabolites within the body may be important for maintaining membrane EPA and DHA levels.

A pathway for conversion of ALNA to EPA and DHA has been identified in rats (Voss et al. 1991; reviewed in Sprecher, 2000). Briefly, ALNA is converted to EPA by the sequential activities of $\Delta 6$ and $\Delta 5$ desaturases and by elongation of the carbon chain. Docosapentaenoic acid (22:5n-3; DPA) is formed by addition of $\mathrm{C}_{2}$ to EPA, which is converted subsequently to $24: 5 n-3$ and $24: 6 n-3$ by further chain elongation and $\Delta 6$ desaturation. DHA is synthesised from $24: 6 n-3$ by peroxisomal $\beta$-oxidation, which shortens the carbon chain by $\mathrm{C}_{2}$. This pathway has also been demonstrated in the pig (Li et al. 2000) and baboons (Su et al. 1999a,b). While $\Delta 6$-desaturase appears to be the rate-limiting step for this pathway, its overall regulation is unclear and may contain several loci of metabolic control including translocation of $24: 6 n-3$ and DHA between the endoplasmic reticulum and peroxisomes (Sprecher, 2000). It has been assumed that hepatic capacity for ALNA conversion and mobilisation from the liver by VLDL represents the major source of newly synthesised EPA and DHA for supply to the periphery. However, since some non-hepatic tissues, in particular brain and

Abbreviations: ALNA, $\alpha$-linolenic acid; AUC, area under the curve; CE, cholesteryl ester; DHA, docosahexaenoic acid; DPA, docosapentaenoic acid; EPA, eicosapentaenoic acid; FAME, fatty acid methyl esters; GC-C-IRMS, gas chromatography-combustion-isotope ratio mass spectrometry; LCPUFA, long-chain polyunsaturated fatty acid; NEFA, non-esterified fatty acid; PC, phosphatidylcholine; TAG, triacylglycerol.

* Corresponding author: Dr G. C. Burdge, fax +44 23 80794945, email g.c.burdge@ soton.ac.uk 
skeletal muscle, express both $\Delta 6$ and $\Delta 5$ desaturases (Cho et al. $1999 a, b)$ it is possible that ALNA conversion within peripheral tissues may also be important for maintaining membrane EPA and DHA concentrations.

In adult men the extent of conversion of ALNA to EPA and DHA has been studied by administration of either ${ }^{2} \mathrm{H}$ or ${ }^{13} \mathrm{C}$-labelled ALNA. Estimates for fractional conversion of labelled ALNA derived from excursions of individual metabolites in plasma show about $8 \%$ was present as EPA, but apparent synthesis of DHA ranged between $0 \%$ (Burdge et al. 2001) to $4 \%$ (Emken et al. 1994). Despite methodological differences between studies, the overall capacity for EPA synthesis in men appears to be limited and conversion to DHA at best constrained severely (Emken et al. 1994; Salem et al. 1999; Vermunt et al. 2000; Burdge et al. 2001). This is consistent with the findings of studies in which increased dietary ALNA intake was not associated with an increase in plasma and/or cell membrane DHA concentration (reviewed by Gerster, 1998). These observations suggest that men may be particularly dependent upon intake of pre-formed DHA for maintenance of membrane DHA concentration.

The extent to which women are able to convert ALNA to EPA, DPA and DHA is not known. As the capacity for essential fatty acid desaturation and chain-elongation appears to be limited in the human fetus (Chambaz et al. 1985), the fetus is dependent upon the effective supply of pre-formed EPA and DHA from the maternal circulation, either from the maternal diet, tissue reserves or synthesis from ALNA. The metabolic demands for DHA by the fetal-placental unit represent a substantial burden for $n-3$ fatty acids upon the mother above that incurred in maintaining her own tissue $n-3$ fatty acid levels in the nonpregnant state, exceeding $860 \mathrm{mg} /$ week in late gestation. This is based upon the sum of estimated accumulation of DHA into the developing brain, liver and adipose tissue (Clandinin et al. 1981), but is likely to be a marked under-representation of the true demands, as it does not include the remaining fetal tissues or placenta. In the absence of a selective increase in dietary DHA intake, such increased demands can only be met by mobilisation of fatty acid stores accumulated before pregnancy and/or the up regulation of ALNA conversion.

Therefore, there is a need to determine whether young women, in the non-pregnant state, are different from men in the way in which they handle $n-3$ PUFA and, in particular, their capacity to form EPA and DHA from dietary ALNA. In the present study we have characterised the metabolic fate of $\left[U_{-}{ }^{13} \mathrm{C}\right] \mathrm{ALNA}$ in young women, in terms of the extent of incorporation into $n$-3 LCPUFA in plasma lipids and partitioning towards $\beta$-oxidation.

\section{Materials and methods}

\section{Materials}

$\left[U_{-}{ }^{13} \mathrm{C}\right] \mathrm{ALNA}(>98$ atom $\%)$ was purchased from Martek Biosciences Corporation (Columbia, ML, USA). This preparation contained $97.1 \%$ ALNA, the remainder being short- and medium-chain fatty acids. Solvents were from Fisher Chemicals Limited (Loughborough, Leics., UK).
Fatty acid standards and all other reagents were obtained from Sigma (Poole, Dorset, UK). BondElut solid phase extraction cartridges were from Varian Limited (Waltonon-Thames, Surrey, UK).

\section{Subjects}

Subjects ( $n$ 6) were healthy women aged $28 \pm 4$ years with BMI $22.4 \pm 2.8 \mathrm{~kg} / \mathrm{m}^{2}$. None of the subjects consumed fish oil dietary supplements or regularly ate oily fish. Routine biochemical analyses of fasting blood lipid concentrations were within ranges regarded as normal (Department of Chemical Pathology, Southampton University Hospitals Trust, Southampton, UK) and none of the subjects had raised concentrations of enzyme markers of hepatic dysfunction. Three subjects regularly used a combined oral contraceptive (30-35 $\mu \mathrm{g} 17 \alpha$-ethynyloestradiol/d) while the others did not take synthetic oestrogens. Ethical approval was granted by the Joint Ethics Committee of Southampton and South West Hampshire and subjects gave written consent.

\section{Administration of $\left[\mathrm{U}^{13}{ }^{13} \mathrm{C}\right] \alpha$-linolenic acid and specimen collection}

All subjects were studied on the tenth day after the start of their menstrual period. The protocol for administration of $\left[{ }^{13} \mathrm{C}\right]$ ALNA was essentially the same as Burdge et al. (2001). Briefly, on the day preceding the start of the study subjects consumed only three standardised meals (total energy $11.2 \mathrm{MJ} / \mathrm{d}$ ) and then fasted overnight for $12 \mathrm{~h}$. On the study day, whole body $\mathrm{CO}_{2}$ excretion was measured by using a GEM indirect calorimeter (PDZEuropa, Crewe, Ches., UK) and a sample of breath was collected at baseline. A blood sample was collected from a forearm vein by venesection using lithium heparin as an anti-coagulant. Subjects then consumed $\left[U-{ }^{13} \mathrm{C}\right]$ ALNA $(700 \mathrm{mg})$ free fatty acid emulsified with double cream $(22 \mathrm{~g})$, casein $(12 \mathrm{~g})$, beet sugar $(4.5 \mathrm{~g})$, glucose $(9 \mathrm{~g})$ and Nesquik milkshake powder (Nestlé, Vevey, Switzerland; $10 \mathrm{~g}$ ). The lipid composition of the test meal was adjusted with sunflower-seed and fish oils so that the fatty acid composition of the combined emulsion and test meal reflected the estimated $n-3$ fatty content of the typical UK diet (Ministry of Agriculture, Fisheries and Food, 1997). The fatty acid composition of the combined test meal and emulsion was confirmed by GC (Table 1). Labelled ALNA was consumed as a drink $(150 \mathrm{ml})$ and accompanied by a standard test breakfast. The total macronutrient and energy contents of the emulsion and test meal are summarised in Table 1. Subjects consumed two further standardised meals at 6 and $12 \mathrm{~h}$ after ingestion of labelled ALNA and then resumed their habitual diet for the remainder of the study period. Breath samples were collected at $2 \mathrm{~h}$ intervals for $12 \mathrm{~h}$ and then at $24 \mathrm{~h}$. Venous blood specimens were collected by venesection at 24,48 , and $72 \mathrm{~h}$ and at 1,2 and 3 weeks.

Preparation of fatty acid methyl esters from plasma lipids Blood samples were separated into plasma and erythrocytes 
Table 1. Fatty acid composition of emulsion and test meal determined by gas chromatographic analysis of total lipid extracts*

\begin{tabular}{lc}
\hline Fatty acid & $\begin{array}{c}\text { Typical mass in test meal } \\
\text { and emulsion }(\mathrm{mg})\end{array}$ \\
\hline $12: 0$ & 1393 \\
$14: 0$ & 4562 \\
$16: 0$ & 11992 \\
$18: 0$ & 5550 \\
$16: 1 n-7$ & 789 \\
$18: 1 n-9$ & 12263 \\
$20: 1$ & 22 \\
$22: 1$ & 14 \\
$18: 2 n-6$ & 7596 \\
$\alpha$-Linolenic acid & $1003^{*} \dagger$ \\
$20: 3 n-6$ & 3 \\
$20: 4 n-6$ & 0 \\
Eicosapentaenoic acid & 56 \\
Docosahexaenoic acid & 46
\end{tabular}

* Total energy intake was $3995 \mathrm{~kJ}$ (protein 10.2\%, carbohydrate $49.1 \%$ and fat $40.7 \%$ ). Total mass of fatty acids was $45.3 \mathrm{~g}$.

† Mass includes $700 \mathrm{mg}\left[U-{ }^{13} \mathrm{C}\right] \alpha$-linolenic acid.

by centrifugation at $1125 \mathrm{~g}$ for $15 \mathrm{~min}$ at $4^{\circ} \mathrm{C}$. Plasma was collected and mixed with protease inhibitors (phenylmethylsulfonylfluoride $1.7 \mu \mathrm{g}$; aprotinin $7 \mu \mathrm{g}$; ethylenediamine tetra-acetic acid $32.2 \mu \mathrm{g} / \mathrm{ml}$ plasma) and stored at $-20^{\circ} \mathrm{C}$. Total lipids were prepared from plasma $(1 \mathrm{ml})$ by extraction with chloroform-methanol (2:1, v/v) (Folch et al. 1957) containing butyrated hydroxytoluene $(50 \mu \mathrm{g} /$ $\mathrm{ml}$ ). Triheptadecanoin, diheptadecanoyl phosphatidylcholine (PC), heneicosanoate and cholesteryl behenate were added as internal standards. Triacylglycerol (TAG), PC, non-esterified fatty acid (NEFA) and cholesteryl esters (CE) were isolated from total lipid extracts by solid phase extraction using aminopropylsilica cartridges (100 mg) and trans-esterified as described (Burdge et al. 2000). Purified lipids were dissolved in toluene and converted to their corresponding fatty acid methyl esters (FAME) by addition of methanol containing $2 \%(\mathrm{v} / \mathrm{v})$ $\mathrm{H}_{2} \mathrm{SO}_{4}$ and incubation at $50^{\circ} \mathrm{C}$ for $18 \mathrm{~h}$. The reaction mixture was neutralised with $0.25 \mathrm{M} \mathrm{KHCO}_{3}$ and $0.5 \mathrm{M} \mathrm{K}_{2} \mathrm{CO}_{3}$ and the FAME extracted with hexane. Samples were dried under $\mathrm{N}_{2}$ before analysis of isotopic enrichment (Burdge et al. 2000).

\section{Analysis of ${ }^{13} \mathrm{C}$ enrichment in plasma fatty acids}

${ }^{13} \mathrm{C}$ enrichment of $n-3$ fatty acids was determined by $\mathrm{GC}-$ combustion-isotope ratio mass spectrometry (GC-CIRMS). FAME were resolved on a $50 \mathrm{~m} \times 0.25 \mu \mathrm{m} \times$ $0.32 \mathrm{~mm}$ BPX-70 fused silica capillary column (SGE Europe Limited, Milton Keynes, UK) using an HP6890 GC (Hewlett Packard, Wokingham, Berks., UK). FAME were converted to $\mathrm{CO}_{2}$ by heating to $860^{\circ} \mathrm{C}$ in the presence of $\mathrm{PtCuO}$ using an Orchid IRMS interface (PDZ-Europa) and ${ }^{13} \mathrm{CO}_{2}:{ }^{12} \mathrm{CO}_{2}$ was determined by a 20/20 Stable Isotope Analyser (PDZ-Europa). Tricosanoic acid methyl ester was used as isotopic enrichment standard (1.135 atom\%). ALNA, EPA, DPA and DHA were all resolved to baseline including complete separation of DPA from 24:0 and 24:1. FAME were identified by their retention times relative to standards. Concentrations of total fatty acids were calculated by integration of baseline-corrected peak areas on chromatograms generated from the total ion current by the GC-C-IRMS. For $1 \mathrm{ml}$ plasma:

(A) target fatty acid concentration $(\mathrm{mol} / \mathrm{l})=($ peak area target fatty acid $\div$ peak area internal standard) $\times$ internal standard $(\mathrm{mol}) \times 1000$;

(B) fractional enrichment determined by interpolation using a calibration curve of fractional enrichment plotted against atom \% enrichment; (B).

(C) concentration of ${ }^{13} \mathrm{C}$-labelled fatty acid $=(\mathrm{A}) \times$

Repeated analysis of the same specimen showed that the $\mathrm{CV}$ for measurement of the concentration of ${ }^{13} \mathrm{C}$-labelled fatty acids in individual plasma lipid classes was consistently less than $4 \%$. This technique was able to resolve ${ }^{13} \mathrm{C}$ enrichment at $0.002 \%$ total fatty acid mass.

\section{Estimation of $\left[{ }^{13}\right.$ C]fatty acid oxidation}

${ }^{13} \mathrm{C}$ enrichment of $\mathrm{CO}_{2}$ excreted on breath was determined by continuous flow isotope ratio MS using an automated breath carbon analyser interface (GSL; PDZ-Europa) and a 20/20 Stable Isotope Analyser (PDZ-Europa) (Jones et al. 1999). Fractional oxidation of labelled fatty acids over $24 \mathrm{~h}$ was calculated from whole body $\mathrm{CO}_{2}$ excretion and ${ }^{13} \mathrm{CO}_{2}$ enrichment on breath (Watkins et al. 1982). No attempt was made to adjust values for retention of ${ }^{13} \mathrm{CO}_{2}$ within bicarbonate pools.

\section{Statistical analysis}

Data are presented as mean and standard error of the mean (SEM) concentrations in plasma. Statistical comparisons both of fatty acid concentrations and areas under the curve (AUC) were carried out by ANOVA using Bonferroni's post hoc correction for multiple comparisons between groups, with the exception of DPA, which was only present in two plasma lipid classes and so was analysed using Student's paired $t$ test.

\section{Results}

\section{Concentrations of n-3 fatty acids in plasma lipids}

Concentrations of total ALNA, EPA, DPA and DHA are summarised in Table 2. Analysis of the fatty acid composition of plasma lipids from fasted subjects at baseline showed n-3 LCPUFA had distinct distributions between classes. The greatest ALNA concentration was in the $\mathrm{CE}$ fraction, which was significantly greater than in PC (3fold), TAG (5-fold) and NEFA (26-fold) fractions. EPA was present in similar concentration in both plasma PC and $\mathrm{CE}$, both of which were significantly greater than that seen in TAG (15-fold) and NEFA (79-fold) fractions (Table 2). DPA was not detected in plasma NEFA and $\mathrm{CE}$, but was present in $\mathrm{PC}$ at a concentration 8-fold greater than in TAG. Plasma PC DHA concentration was significantly greater than in CE (2-fold), TAG (17-fold) and NEFA (41-fold). 
Table 2. Concentrations of total $n$-3 long-chain polyunsaturated fatty acids in plasma lipids at baseline for six fasted women

(Mean values and standard errors of the mean)

\begin{tabular}{|c|c|c|c|c|c|c|c|c|}
\hline & \multicolumn{8}{|c|}{ Concentration $(\mu \mathrm{mol} / \mathrm{l})$} \\
\hline & \multicolumn{2}{|c|}{ TAG } & \multicolumn{2}{|c|}{ NEFA } & \multicolumn{2}{|c|}{ PC } & \multicolumn{2}{|c|}{ CE } \\
\hline & Mean & SEM & Mean & SEM & Mean & SEM & Mean & SEM \\
\hline ALNA & $27 \cdot 2^{\mathrm{a}} \mathrm{t}^{\mathrm{b} * \mathrm{c}} \dagger$ & $6 \cdot 7$ & $4 \cdot 8^{\mathrm{d}} \dagger^{, \mathrm{e}} \ddagger$ & 0.7 & $40 \cdot 0^{f} \ddagger$ & $7 \cdot 7$ & $124 \cdot 9$ & 29.5 \\
\hline EPA & $3.5^{\mathrm{a} * \mathrm{~b}}+, \mathrm{c}_{\dagger}$ & 0.6 & $0.7^{\mathrm{d}} \mathrm{e}_{\dagger}^{\mathrm{t}}$ & 0.1 & 51.4 & $9 \cdot 1$ & $55 \cdot 2$ & 31.9 \\
\hline DPA & $5 \cdot 1^{\mathrm{b}}+$ & 0.9 & ND & & 38.7 & $7 \cdot 7$ & ND & \\
\hline $\mathrm{DHA}$ & $10 \cdot 4^{\mathrm{a} * \mathrm{~b}} \neq, \mathrm{c} \dagger$ & $2 \cdot 8$ & $4 \cdot 4^{\mathrm{d}}{ }^{, \mathrm{e}} \dagger$ & 0.3 & $181 \cdot 2^{f_{*}}$ & $19 \cdot 2$ & $77 \cdot 8$ & 21.4 \\
\hline
\end{tabular}

TAG, triacylglycerol; NEFA, non-esterified fatty acids; PC, phosphatidylcholine; CE, cholesteryl ester; ALNA, $\alpha$-linolenic acid; EPA, eicosapentaenoic acid; DPA, docosapentaenoic acid; DHA, docosahexaenoic acid; ND, not detected.

Significant differences between lipid classes are indicated by: ${ }^{\mathrm{a}} \mathrm{TAG} v$. NEFA, ${ }^{\mathrm{b}} \mathrm{TAG} v$. PC, ${ }^{\mathrm{c}} \mathrm{TAG} v$. CE,

${ }^{d}$ NEFA $v$. PC, ${ }^{e}$ NEFA $v$. CE and ${ }^{f} P C$ v. CE. Comparisons between lipid classes for ALNA, EPA and DHA

were by ANOVA while comparisons between TAG and PC for DPA was by Student's unpaired $t$ test.

Mean values in a row were significantly different: ${ }^{\star} P<0.01, \dagger P<0.001, \ddagger P<0.0001$.

\section{Handling of $\left[{ }^{13} \mathrm{C}\right] \alpha$-linolenic acid in plasma}

The excursions of labelled fatty acids in plasma lipids between $24 \mathrm{~h}$ and $21 \mathrm{~d}$ are summarised in Figs. 1 and 2. Labelled ALNA was detected in all four lipid classes at $24 \mathrm{~h}$ (Fig. 1). $\left[{ }^{13} \mathrm{C}\right]$ ALNA concentration was greatest in the plasma TAG at $24 \mathrm{~h}(0.47$ (SEM 0.11) $\mu \mathrm{mol} / \mathrm{l})$, reached approximately half-maximum values (0.22 (SEM $0 \cdot 10)$ $\mu \mathrm{mol} / \mathrm{l})$ by $48 \mathrm{~h}$ and had decreased to baseline by $21 \mathrm{~d}$ (Fig. 1). The time-course of $\left[{ }^{13} \mathrm{C}\right] \mathrm{ALNA}$ in plasma PC and NEFA fractions was similar to that seen in the TAG fraction. $\left[{ }^{13} \mathrm{C}\right] \mathrm{ALNA}$ concentration in NEFA at $24 \mathrm{~h}$ was 0.08 (SEM 0.02) $\mu \mathrm{mol} / \mathrm{l}$, which decreased to approximately half-maximum level by $48 \mathrm{~h}(0.04$ (SEM $0 \cdot 01) \mu \mathrm{mol} / \mathrm{l})$ and returned to baseline by $21 \mathrm{~d}$ (Fig. 1). In plasma PC, labelled ALNA concentration was greatest at $24 \mathrm{~h}(0.99$ (SEM 0.29) $\mu \mathrm{mol} / \mathrm{l})$, decreasing to half-maximum levels by $48 \mathrm{~h}(0.32$ (SEM 0.08) $\mu \mathrm{mol} / \mathrm{l}$ ) and reached baseline enrichment by $21 \mathrm{~d}$ (Fig. 1). $\left[{ }^{13} \mathrm{C}\right]$ ALNA concentration in the CE fraction at $24 \mathrm{~h}$ was 2.0 (SEM 1.0) $\mu \mathrm{mol} / \mathrm{l}$, which decreased to approximately half-maximum concentration by $72 \mathrm{~h}(1.15$ (SEM 0.37) $\mu \mathrm{mol} / \mathrm{l}$ ) and returned to baseline by $21 \mathrm{~d}$ (Fig. 1). The relative excursions of $\left[{ }^{13} \mathrm{C}\right] \mathrm{ALNA}$ in plasma lipids were calculated from summation of the absolute excursion of labelled ALNA in each lipid class (Table 3) and expressed as a percentage: TAG 9.2, NEFA 2.1, PC $10 \cdot 5$ and CE 78.2. Therefore, $\left[{ }^{13} \mathrm{C}\right]$ ALNA was associated predominately with the $\mathrm{CE}$ fraction over

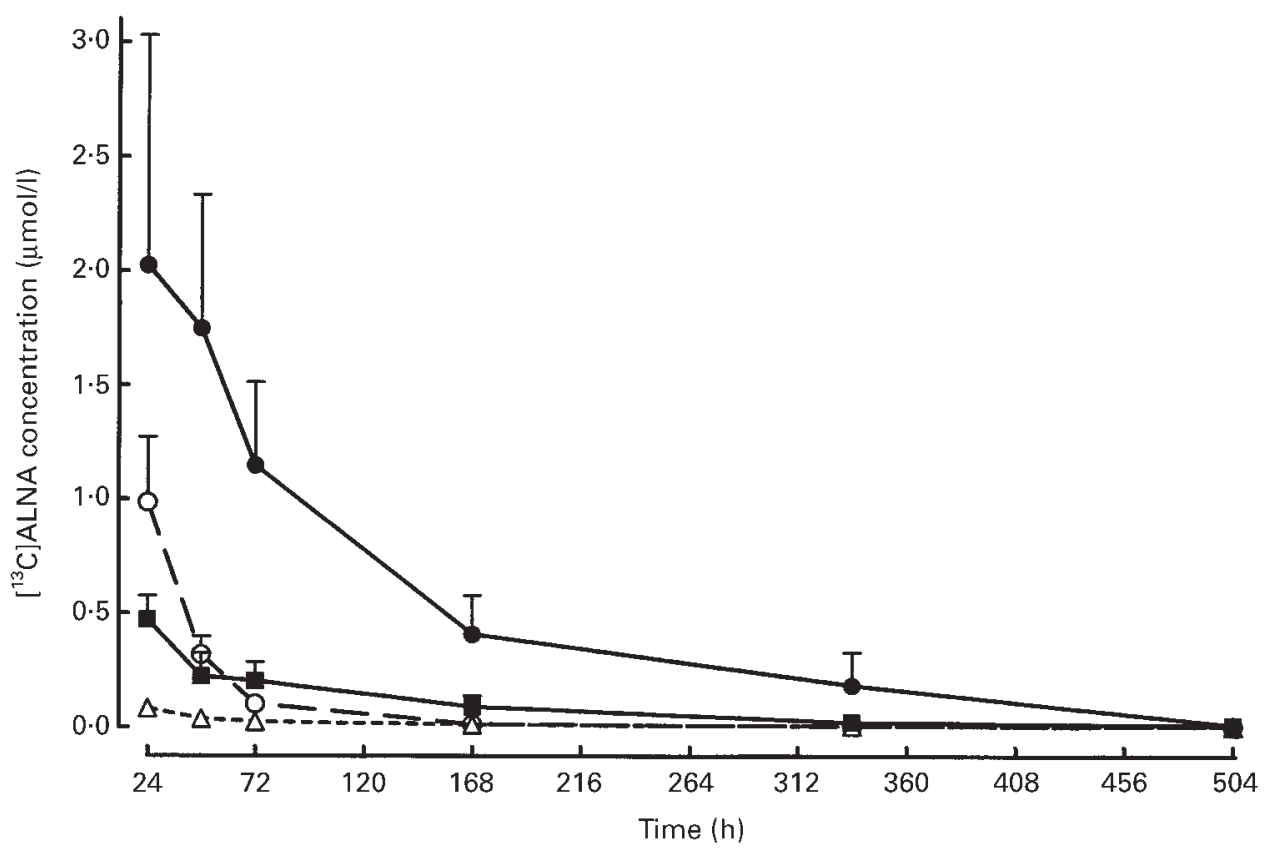

Fig. 1. Excursion of $\left[{ }^{13} \mathrm{C}\right] \alpha$-linolenic acid (ALNA) in plasma lipids over $21 \mathrm{~d}$. Mean values for six women are shown with standard errors of the mean represented by vertical bars. $(\mathbf{\square})$, Triacylglycerol; $(\triangle)$, nonesterified fatty acid; $(\bigcirc)$, phosphatidylcholine; $(\bullet)$, cholesteryl ester concentrations in plasma. 
Table 3. Excursions of individual $\left[{ }^{13} \mathrm{C}\right]$-labelled $n$-3 fatty acids in plasma lipids over $21 \mathrm{~d}$

\begin{tabular}{|c|c|c|c|c|c|c|c|c|}
\hline & \multicolumn{8}{|c|}{$\mathrm{AUC}(\mu \mathrm{mol} / \mathrm{l} \times \mathrm{d})$} \\
\hline & \multicolumn{2}{|c|}{ TAG } & \multicolumn{2}{|c|}{ NEFA } & \multicolumn{2}{|c|}{$P C$} & \multicolumn{2}{|c|}{ CE } \\
\hline & Mean & SEM & Mean & SEM & Mean & SEM & Mean & SEM \\
\hline ALNA & $26 \cdot 3^{\mathrm{a}} \dagger^{, \mathrm{c}} \dagger$ & $4 \cdot 8$ & $5.9^{\mathrm{d}} \dagger^{, \mathrm{e}} \dagger$ & 0.5 & $30 \cdot 2^{f t}$ & 4.5 & 224.4 & $70 \cdot 1$ \\
\hline EPA & $3 \cdot 3^{\mathrm{a}}, \mathrm{b}, \mathrm{b}, \mathrm{c} *$ & 0.9 & $0.3^{\mathrm{d}}+\mathrm{e}_{\dagger}$ & 0.1 & $42 \cdot 2$ & $7 \cdot 8$ & 41.5 & 8.9 \\
\hline DPA & $3 \cdot 2^{b *}$ & $1 \cdot 1$ & ND & & $17 \cdot 7^{\mathrm{a} *}$ & 3.8 & ND & \\
\hline $\mathrm{DHA}$ & $3 \cdot 8^{a_{\star}, \mathrm{b}} \dagger$ & $2 \cdot 0$ & $0.5^{\mathrm{d}} \boldsymbol{t}^{, \mathrm{e} *}$ & 0.2 & $26 \cdot 8^{f} \dagger$ & $7 \cdot 0$ & $2 \cdot 9$ & $1 \cdot 1$ \\
\hline
\end{tabular}

TAG, triacylglycerol; NEFA, non-esterified fatty acids; PC, phosphatidylcholine; CE, cholesteryl ester; ALNA, $\alpha$-linolenic acid; EPA, eicosapentaenoic acid; DPA, docosapentaenoic acid; DHA, docosahexaenoic acid; ND, not detected.

Significant differences between lipid classes are indicated by: ${ }^{\text {T}}$ TAG $v$. NEFA, ${ }^{\text {b} T A G ~} v$. PC, ${ }^{\mathrm{c}}$ TAG $v$. CE,

${ }^{\mathrm{d}}$ NEFA $v$. PC, ${ }^{e}$ NEFA v. CE and ${ }^{\text {f } P C ~} v$. CE. Comparisons between lipid classes for ALNA, EPA and DHA were by ANOVA while comparison between TAG and PC for DPA was by Student's unpaired $t$ test.

Mean values in a row were significantly different: ${ }^{\star} P<0.01, \dagger P<0.001$.

the 3-week period following ingestion of the labelled test meal.

\section{Handling of labelled eicosapentaenoic acid, docosapentaenoic acid and docosahexaenoic acid in plasma}

The time-courses of the excursions of labelled EPA, DPA and DHA are summarised in Fig. 2. In plasma TAG, $\left[{ }^{13} \mathrm{C}\right] \mathrm{EPA}$ concentration was greatest at $24 \mathrm{~h}$ (36 (SEM 8) nmol/l) and decreased to baseline by $14 \mathrm{~d}$ (Fig. 2 (a)). Labelled DPA followed a similar time-course to EPA, with maximum concentration at $24 \mathrm{~h}$ (26 (SEM 7) nmol/l) decreasing to baseline by $12 \mathrm{~d}$. Peak $\left[{ }^{13} \mathrm{C}\right] \mathrm{DHA}$ concentration was at $48 \mathrm{~h}(12$ (SEM 6) nmol/l), which returned to baseline by $21 \mathrm{~d}$. The relative excursions of labelled $n$ 3 fatty acids in plasma TAG were: ALNA 71.9\%; EPA $9.0 \%$; DPA $8.7 \%$; DHA $10.4 \%$ (Table 3).

Incorporations of both $\left[{ }^{13} \mathrm{C}\right] \mathrm{EPA}$ and $\left[{ }^{13} \mathrm{C}\right] \mathrm{DHA}$ were detected in plasma NEFA (Fig. 2). However, there was no detectable incorporation of $\left[{ }^{13} \mathrm{C}\right] \mathrm{DPA}$ above baseline ${ }^{13} \mathrm{C}$ abundance in the NEFA fraction. Maximum concentrations of labelled fatty acids were: EPA 2.2 (SEM 0.8) $\mathrm{nmol} / \mathrm{l}$ at $48 \mathrm{~h}$; DHA 1.0 (SEM 0.7$) \mathrm{nmol} / 1$ at $72 \mathrm{~h}$. The relative excursions of $\left[{ }^{13} \mathrm{C}\right]$ fatty acids in plasma NEFA were: ALNA 88.0\%; EPA $4.5 \%$; DPA $0 \%$; DHA $7.5 \%$ (Table 3).

$\left[{ }^{13} \mathrm{C}\right]$ EPA concentration was greatest in plasma $\mathrm{PC}$ at $24 \mathrm{~h}$ (418 (SEM 85) nmol/l), which decreased to baseline over the subsequent $20 \mathrm{~d}$ (Fig. 2). Peak $\left[{ }^{13} \mathrm{C}\right] \mathrm{DPA}$ concentration in plasma PC was at $72 \mathrm{~h}$ (88 (SEM 24) nmol/l), which returned to baseline enrichment by $21 \mathrm{~d}$. Maximum $\left[{ }^{13} \mathrm{C}\right] \mathrm{DHA}$ concentration in plasma PC occurred later than for labelled EPA and DPA at $7 \mathrm{~d}$ (79 (SEM 23) nmol/1), and remained significantly $(P<0.01)$ elevated above baseline ${ }^{13} \mathrm{C}$ abundance at $21 \mathrm{~d}$ (31 (SEM 9) nmol/l). The relative excursions of ${ }^{13} \mathrm{C}$-labelled $n$-3 fatty acids in plasma PC were: ALNA 25.8\%; EPA 36.1\%; DPA $15.2 \%$; DHA $22.9 \%$ (Table 3 ).

Peak $\left[{ }^{13} \mathrm{C}\right]$ EPA concentration in plasma $\mathrm{CE}$ was at $72 \mathrm{~h}$ (213 (SEM 56) nmol/l), which decreased to baseline by $21 \mathrm{~d}$ (Fig. 2 (d)). There was no detectable incorporation of $\left[{ }^{13} \mathrm{C}\right] \mathrm{DPA}$ into plasma $\mathrm{CE}$ above baseline ${ }^{13} \mathrm{C}$ abundance over $21 \mathrm{~d} .{ }^{13} \mathrm{C}$ enrichment of DHA in plasma CE was marginal with a peak concentration of 4 (SEM 2) nmol/1 at $48 \mathrm{~h}$. The relative excursions of labelled ALNA metabolites in plasma CE were: ALNA 83.5\%; EPA $15.4 \%$; DPA $0 \%$; DHA $1.1 \%$.

Calculation of the AUC for each of the labelled $n-3$ fatty acids in plasma over $21 \mathrm{~d}$ showed a differential distribution between lipid classes (Table 3). $\left[{ }^{13} \mathrm{C}\right] \mathrm{ALNA}$ was carried predominately as plasma $\mathrm{CE}$ ( $\geq 7$-fold compared with the other plasma lipid classes). The excursion of labelled EPA was similar in plasma PC and CE, both of which were substantially greater $(>13$-fold) than in TAG or NEFA. Both $\left[{ }^{13} \mathrm{C}\right] \mathrm{DPA}$ and $\left[{ }^{13} \mathrm{C}\right] \mathrm{DHA}$ were carried principally in plasma $\mathrm{PC}$ (both $>5$-fold compared with other lipid classes) (Table 3 ).

The excursion of labelled $n-3$ fatty acids in total plasma lipids has been used previously to estimate the apparent fractional conversion of ALNA to longer-chain fatty acids (Emken et al. 1994; Burdge et al. 2001). Summation of the excursion of each fatty acid in all four plasma lipids expressed as a proportion of the total excursion of $\left[{ }^{13} \mathrm{C}\right] n-3$ fatty acids showed that the fractional distributions of labelled fatty acids were: ALNA 63.7 (SEM 4.0) \%; EPA 21.1 (SEM 2.1) \%; DPA 5.9 (SEM 1.4) \%; DHA 9.2 (SEM $2.9) \%$. The fractional excursion of $\left[{ }^{13} \mathrm{C}\right] \mathrm{DHA}$ in plasma $\mathrm{PC}$ tended to be greater in the women using the contraceptive pill (individual values $40.3,30.0,29.0 \mu \mathrm{mol} / 1 \times \mathrm{d}$ ) compared with the non-pill users (individual values $22 \cdot 8$, $3 \cdot 0,13 \cdot 4 \mu \mathrm{mol} / 1 \times \mathrm{d})$.

\section{Recovery of labelled fatty acid as ${ }^{13} \mathrm{CO}_{2}$ on breath}

Recovery of $\left[{ }^{13} \mathrm{C}\right] \mathrm{ALNA}$ on breath derived from integration of the AUC of the excursion of labelled $\mathrm{CO}_{2}$ on breath over $24 \mathrm{~h}$ and whole body $\mathrm{CO}_{2}$ excretion indicated that 22.2 (SEM 1.5) \% of the administered dose of labelled ALNA was recovered as ${ }^{13} \mathrm{CO}_{2}$ over the first $24 \mathrm{~h}$ of the study. There was no detectable enrichment in breath ${ }^{13} \mathrm{CO}^{2}$ above baseline abundance after $24 \mathrm{~h}$.

\section{Discussion}

The present study is the first that specifically characterises 

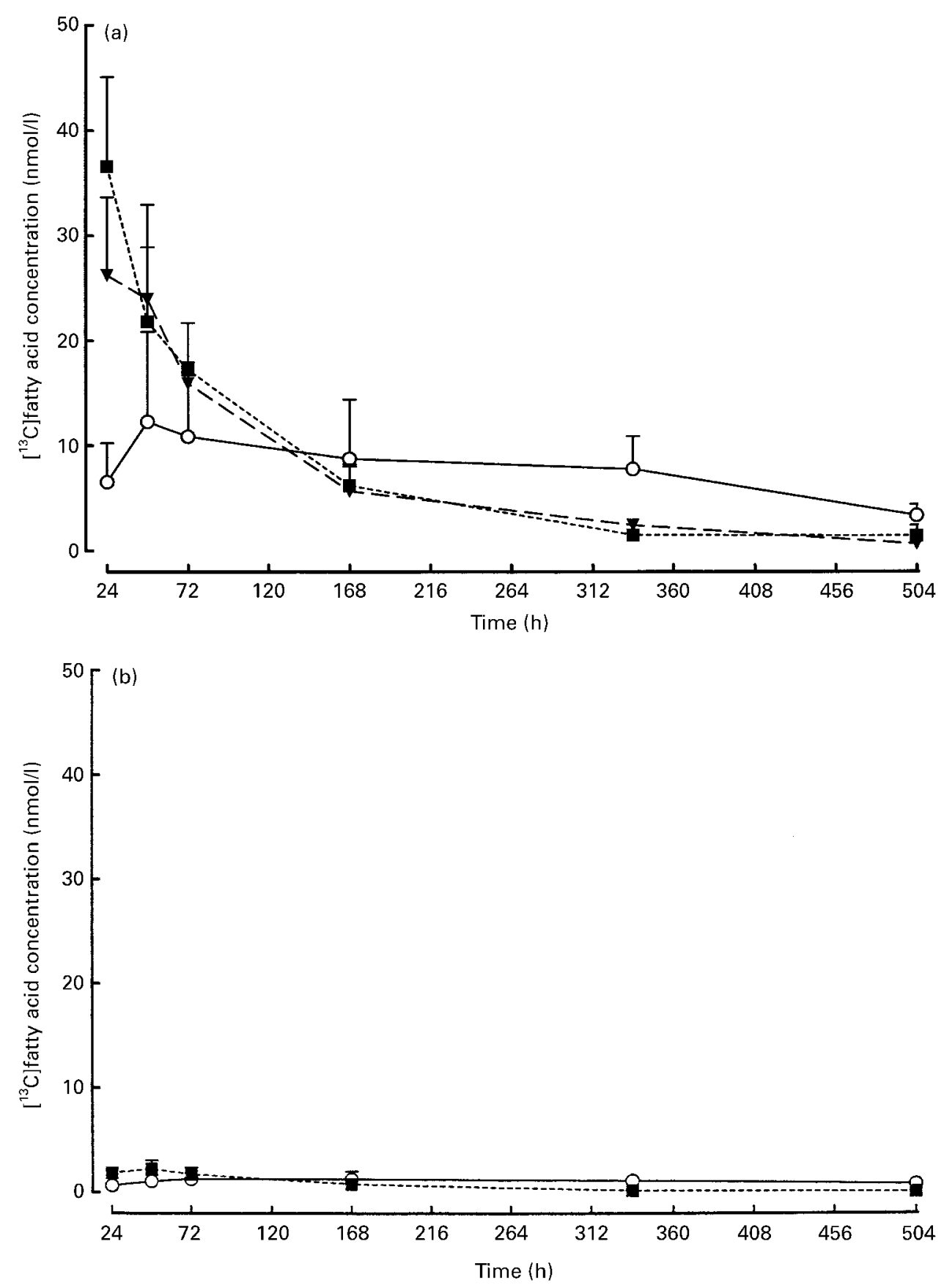

the metabolism of ALNA in young women. These findings show differential partitioning of individual metabolites between plasma lipid classes, significant conversion to EPA, DPA and DHA and marked conversion to $\mathrm{CO}_{2}$ by $\beta$-oxidation. These data indicate that plasma $\mathrm{CE}$ may act as a long-term source of ALNA within the circulation while EPA, DPA and DHA were associated primarily with PC. In comparison with previous studies, it also appears that the metabolic capacity for conversion of ALNA to DHA may be substantially greater in women than in men.

In studies conducted in young men, we have shown that $\left[{ }^{13} \mathrm{C}\right]$ ALNA appears as TAG in the circulation during the early postprandial period (up to $10 \mathrm{~h}$ ), which represents the mobilisation of ingested labelled fatty acid from the enterocyte (Burdge et al. 2001). Labelled ALNA in TAG almost completely returns to baseline within $24 \mathrm{~h}$, so any $\left[{ }^{13} \mathrm{C}\right]$ ALNA that remains in the TAG fraction after the first $24 \mathrm{~h}$ most probably represents hepatic mobilisation of labelled PUFA as VLDL TAG. The results of the present study focus on the subsequent partitioning of ALNA and $n-3$ LCPUFA metabolites in plasma after the initial postprandial period. In young women, the excursion of labelled ALNA in plasma TAG and PC followed a similar time-course to men (Burdge et al. 2001). However, $\left[{ }^{13} \mathrm{C}\right]$ ALNA was present in plasma $\mathrm{CE}$ for up to $21 \mathrm{~d}$, 

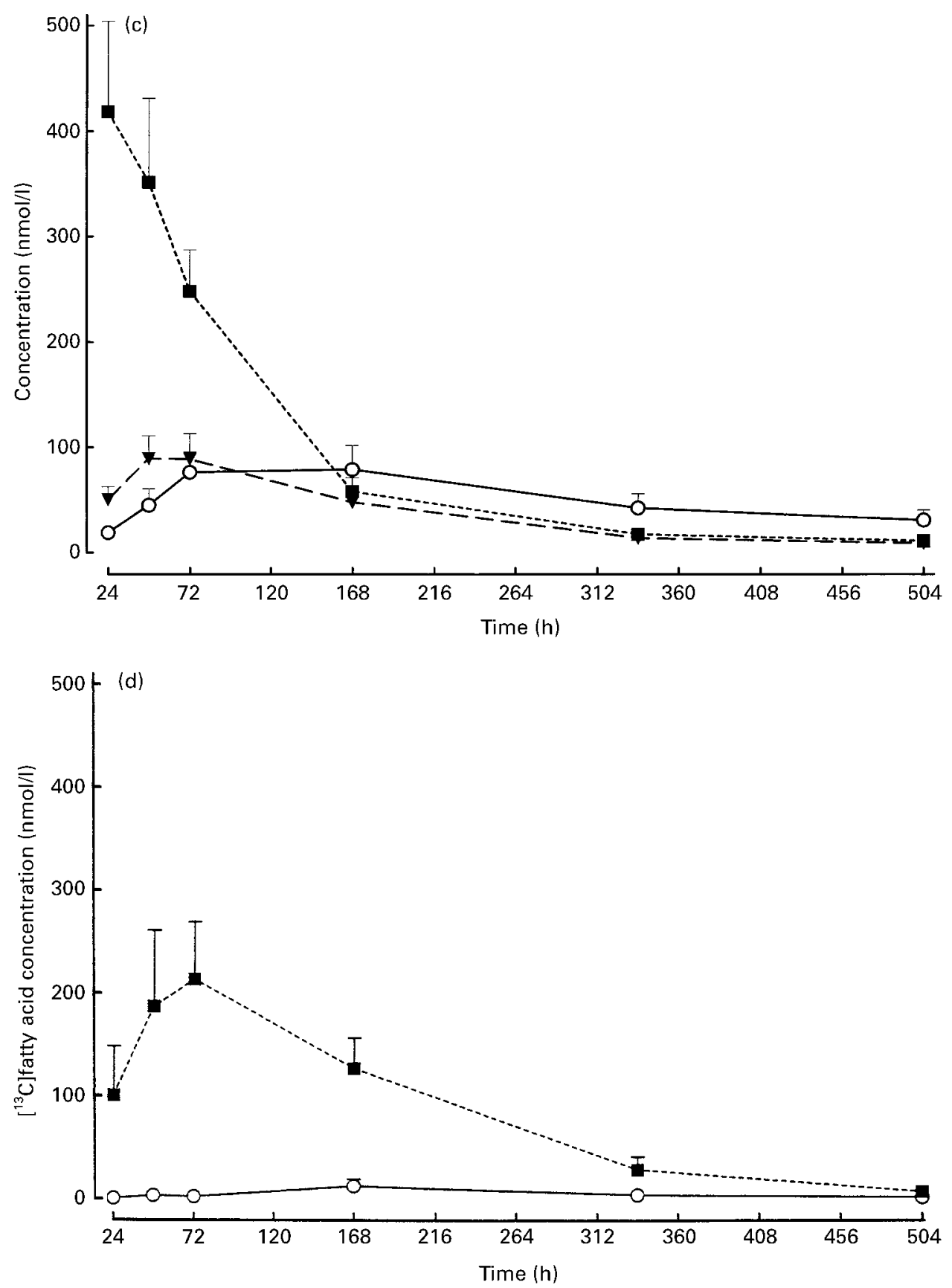

Fig. 2. Excursion of $(\boldsymbol{\square}),\left[{ }^{13} \mathrm{C}\right]$ eicosapentaenoic acid; $(\boldsymbol{\nabla}),\left[{ }^{13} \mathrm{C}\right]$ docosapentaenoic acid; $(\mathrm{O}),\left[{ }^{13} \mathrm{C}\right]$ docosahexaenoic acid in plasma lipids over $21 \mathrm{~d}$. Mean values for six women are shown with standard errors of the mean represented by vertical bars. (a), Triacylglycerol; (b), non-esterified fatty acid; (c), phosphatidylcholine; (d), cholesteryl ester $\left[{ }^{13} \mathrm{C}\right]$ fatty acid concentrations.

with half-maximum concentration at about $7 \mathrm{~d}$ (Fig. 1). Whether this is specific to women is not clear as analysis of $\left[{ }^{13} \mathrm{C}\right] \mathrm{ALNA}$ incorporation into plasma $\mathrm{CE}$ has not been previously reported in men. This suggests that $\left[{ }^{13} \mathrm{C}\right] \mathrm{ALNA}$ incorporation into $\mathrm{CE}$ by the liver and mobilisation on VLDL and/or CE synthesis from $\mathrm{PC}$ by the action of lecithin-cholesterol acyl transferase may serve as a mechanism for delivery of ALNA to peripheral tissues. One potential consequence of this observation is that tissues with active desaturation and elongation pathways may be able to maintain membrane EPA, DPA and DHA levels independent of pre-formed metabolites from the liver by taking up ALNA from CE in the circulation. This is supported by the observation that brain, lung and skeletal muscle have substantial expressions of both $\Delta 6$ and $\Delta 5$ desaturases (Cho et al. 1999a,b). Conversely, tissues with low expressions of these enzymes, such as kidney and pancreas (Cho et al. 1999a,b), may be dependent upon the supply of pre-formed EPA, DPA and DHA either from the diet or from hepatic ALNA conversion. 
Conversion of $\left[{ }^{13} \mathrm{C}\right]$ ALNA to EPA, DPA and DHA was detected in all six individuals. EPA was carried to a similar extent in both plasma $\mathrm{CE}$ and $\mathrm{PC}$, while the highest concentrations of labelled DPA and DHA were in the PC fraction. These reflect largely the distribution of total $n-3$ fatty acids between plasma lipid classes. Such differential distribution suggests that incorporation of newly synthesised LCPUFA into plasma lipids is a primary determinant of the $n-3$ fatty acid composition of these lipid classes. Alternatively, the differential distribution of both total and labelled fatty acids between plasma lipid classes may reflect the net product of the specificity of hepatic lipid synthesis, and selective turnover and removal from the circulation. It may be that both processes contribute to the net $n-3$ content of plasma TAG, CE and PC. The high concentration of both total and labelled EPA and DHA in plasma PC suggests that PC may play an important role in supplying these fatty acids pre-formed to peripheral tissues.

The extent of ALNA conversion to DHA in these young women was greater than reported in previous studies in men, although direct comparisons are difficult due to differences between studies in the chemical form of labelled ALNA, the meal context in which it was administered and the size of dose given. The relative excursions of labelled fatty acids in plasma have been used previously to estimate fractional conversion of ALNA to longer-chain metabolites (Emken et al. 1994; Burdge et al. 2001). The limitation of this approach is that it probably reflects an underestimate of hepatic conversion due to partitioning of metabolites into storage pools and towards $\beta$-oxidation, and differential incorporation into and turnover within plasma lipids. However, in the absence of techniques for measuring hepatic ALNA conversion directly the results of such calculations are useful for comparative purposes within and between studies. In the present study the fractional excursions of labelled fatty acids in total plasma lipids was EPA $21 \%$, and DHA $9 \cdot 2 \%$. Previous estimates of ALNA inter-conversion in young men showed lower fractional excursions of both EPA and DHA (EPA $8 \%$, and DHA 4\% (Emken et al. 1994); EPA 7.9\%, DHA $0 \%$ (Burdge et al. 2001)). These data suggest greater synthesis of both EPA and DHA in women compared with men. The relative excursions of EPA and DHA in plasma PC in young women were approximately 36 and $22 \%$, respectively. Thus while the fractional excursion of EPA was similar to that which we reported previously in young men over $21 \mathrm{~d}$ (36\%) (Burdge et al. 2001), the relative AUC for DHA was substantially greater in women than in men $(0 \%)$. This is consistent with the observation that the total fractional excursions of EPA, DPA and DHA in plasma PC were greater in young women (74\%) than reported in men $(59.6 \%)$ (Emken et al. 1994). Other reports of the metabolism of labelled ALNA in adults have not described the handling of longer-chain metabolites in individual plasma lipid classes. Direct comparisons between the present study and those reported by Salem et al. (1999) and Vermunt et al. (2000) are also difficult as the gender composition of the subject group reported by the former was not disclosed and the volunteers in the latter study were an undefined mixture of men and women. However, both studies reported lower peak concentrations of $\left[{ }^{13} \mathrm{C}\right] \mathrm{EPA}$ (approximately 150 and $123 \mathrm{nmol} / \mathrm{l}$, respectively, re-calculated from published data) and $\left[{ }^{13} \mathrm{C}\right] \mathrm{DHA}$ (4 and $5 \mathrm{nmol} / \mathrm{l}$, respectively) than presented here for PC alone. Together these observations indicate that EPA and DHA synthesis was greater in women in the present study in both absolute as well as relative amounts.

Unfortunately, as there appear to be no direct comparisons of plasma $n-3$ fatty acid concentrations between men and women, the extent to which these apparent gender differences in ALNA conversion are reflected in the circulating concentrations of these fatty acids is not clear.

The major increase in conversion of $\left[{ }^{13} \mathrm{C}\right] \mathrm{ALNA}$ to longer-chain metabolites was in DHA synthesis. The similarity in the excursion of $\left[{ }^{13} \mathrm{C}\right] \mathrm{EPA}$ accompanied by a lower fractional excursion of labelled DPA in young women (15\%) compared with men (34\%) (Burdge et al. 2001) together with substantially greater fractional AUC for $\left[{ }^{13} \mathrm{C}\right] \mathrm{DHA}$ in women $(23 \%)$ than in men $(0 \%)$ suggests up regulation of the desaturation and elongation pathway down-stream of EPA synthesis resulting in increased conversion of DPA to DHA. While it is possible that conversion of $24: 5 n-3$ to $24: 6 n-3$ by $\Delta 6$-desaturase activity may have been up regulated, these observations are also consistent with increased flux through the peroxisomal $\beta$-oxidation step, which has been proposed as a locus of control of this pathway (Sprecher, 2000).

The greater conversion of ALNA to DHA in pill users compared with non-pill users, and previous studies in both women (Silfverstolpe et al. 1981; Ottosson et al. 1984) and rats (Eden et al. 1987), suggests that one possible explanation for the greater apparent synthesis of DHA in women compared with men may be up regulation of the desaturation and elongation pathway by oestrogen. If true, the capacity to regulate ALNA conversion by the action of sex hormones may contribute to the physiological increase in maternal plasma DHA concentration in pregnancy (Neuringer et al. 1984; Burdge et al. 1994; Burdge \& Postle, 1994; Postle et al. 1995; Otto et al. 1997).

Estimates of $\left[{ }^{13} \mathrm{C}\right]$ ALNA fractional oxidation showed that $22 \%$ of administered fatty acid was recovered as ${ }^{13} \mathrm{CO}_{2}$ over $24 \mathrm{~h}$. However, trapping of ${ }^{13} \mathrm{CO}_{2}$ in bicarbonate pools within the body may have resulted in a $30 \%$ underestimate of actual extent of $\left[{ }^{13} \mathrm{C}\right] \mathrm{ALNA}$ oxidation (Irving et al. 1983) and so up to $29 \%$ of labelled fatty acid may have been used as an energy source over the 'first $24 \mathrm{~h}$ of the study. Fractional oxidation of $\left[{ }^{13} \mathrm{C}\right]$ ALNA in women was about $27 \%$ lower than we have observed previously in young men $32 \%$ administered dose over $24 \mathrm{~h}$ uncorrected for trapping in bicarbonate pools; GC Burdge, AE Jones and SA Wootton, unpublished results). Although this may suggest selective sparing of ALNA from $\beta$-oxidation in women, $\left[{ }^{13} \mathrm{C}\right]$ palmitate oxidation has also been shown to be lower in women compared with men (Jones et al. 1998, 1999) and at a comparable level to that reported here for $\left[{ }^{13} \mathrm{C}\right] \mathrm{ALNA}$, possibly reflecting, in part, lower rates of energy metabolism in women. Thus, as in men (Burdge et al. 2001), there does not appear to be any selective sparing or use of ALNA as an 
energy source. In addition, women tend to use carbohydrate as the preferred metabolic fuel in both the fasted (Toth et al. 1998) and postprandial state (Jones et al. 1998). Thus although lower ALNA oxidation in women may not reflect differential selection of fatty acid species for use as metabolic fuels, the net result may be to increase availability of ALNA for supply to the liver either for further inter-conversion and mobilisation as $\mathrm{PC}$ or for export without modification as CE by VLDL. Both processes would potentially increase availability of $n-3$ fatty acids to peripheral tissues.

Together these data indicate that hepatic capacity for conversion of ALNA to DHA and the subsequent mobilisation of both ALNA and longer-chain $n$-3 fatty acids from the liver are important determinants of the supply of these fatty aids to peripheral tissues in women. One implication of these observations is that EPA and DHA status in these women may depend substantially upon the metabolic capacity for ALNA conversion. Thus variations in metabolic capacity for ALNA desaturation and elongation, which may be due in part to differences in oestrogen exposure rather than diet alone, may be an important source of differing EPA and DHA status between individuals. Such regulatory influences may account in part for the $25 \%$ variation in maternal DHA status observed between pregnant women (Postle et al. 1995). Whether such variation in metabolic capacity for ALNA conversion and/or the magnitude and mobilisation of body DHA stores leads to differences in tissue function in women or in fetal development remain to be established.

\section{Acknowledgements}

We would like to thank Dr A. E. Jones and Miss L. Ware for assistance during the metabolic studies, Mr P. Wright for sample preparation and Mrs A. Hounslow for measurement of ${ }^{13} \mathrm{CO}_{2}$ enrichment.

\section{References}

Burdge GC, Hunt AN \& Postle AD (1994) Mechanisms of hepatic phosphatidylcholine synthesis in adult rat: effects of pregnancy. Biochemical Journal 303, 941-947.

Burdge GC, Jones AE, Wright P, Ware L \& Wootton SA (2001) $\alpha$-Linolenic acid metabolism in adult men: evidence for synthesis of eicosapentaenoic and docosapentaenoic acids, but not docosahexaenoic acid. Proceedings of the Nutrition Society 60, 22A.

Burdge GC \& Postle AD (1994) Hepatic phospholipid molecular species in the guinea pig. Adaptations to pregnancy. Lipids 29, 259-264.

Burdge GC, Wright P, Jones AE \& Wootton SA (2000) A method for separation of phosphatidylcholine, triacylglycerol, nonesterified fatty acids and cholesterol esters from plasma by solid phase extraction. British Journal of Nutrition 84, $781-787$.

Calder PC (1999) Dietary fatty acids and the immune system. Lipids 34, S137-S140.

Chambaz J, Ravel D, Manier MC, Pepin D, Mulliez N \& Bereziat G (1985) Essential fatty acid interconversion in the human liver. Biology of the Neonate 47, 136-140.

Cho HP, Nakamura M \& Clarke SD (1999a) Cloning, expression and nutritional regulation of the mammalian $\Delta-6$ desaturase. Journal of Biological Chemistry 274, 471-477.

Cho HP, Nakamura M \& Clarke SD (1999b) Cloning, expression and fatty acid regulation of the human $\Delta-5$ desaturase. Journal of Biological Chemistry 274, 37335-37339.

Clandinin MT, Chappell JE, Hein T, Swyer PR \& Chance GW (1981) Fatty acid utilization in perinatal de novo synthesis of tissues. Early Human Development 5, 355-366.

Eden S, Oscarsson J, Jansson JO \& Svanborg A (1987) The influence of gonadal steroids and the pituitary on the levels and composition of plasma phospholipids in the rat. Metabolism 36, 527-532.

Emken EA, Adolf RO \& Gully RM (1994) Dietary linoleic acid influences desaturation and acylation of deuterium-labelled linoleic and linolenic acids in young adult males. Biochimica et Biophysica Acta 1213, 277-288.

Folch JL, Lees M \& Sloane-Stanley GH (1957) A simple method for the isolation and purification of total lipides from animal tissues. Journal of Biological Chemistry 226, 497-509.

Gerster H (1998) Can adults convert $\alpha$-linolenic acid (18:3n-3) to eicosapentaenoic acid (20:5n-3) and docosahexaenoic acid (22:5n-3)? International Journal of Vitamin and Nutrition Research 68, 159-173.

Innis SM (1991) Essential fatty acids in growth and development. Progress in Lipid Research 30, 39-103.

Irving CS, Wong WW, Schulman RJ, Smith EO \& Klein PD (1983) $\left[{ }^{13} \mathrm{C}\right]$ Bicarbonate kinetics in humans: intra- vs. interindividual variations. American Journal of Physiology 245, R190-R202.

Jones AE, Murphy JL, Stolinski M \& Wootton SA (1998) The effect of age and gender on the metabolic disposal of $1-{ }^{13} \mathrm{C}$ palmitic acid. European Journal of Clinical Nutrition 52, 22-28.

Jones AE, Stolinski M, Smith RD, Murphy JL \& Wootton SA (1999) Effect of fatty acid chain length and saturation on the gastrointestinal handling and metabolic disposal of dietary fatty acids in women. British Journal of Nutrition 81, 37-43.

Li Z, Kaplan ML \& Hatchey DL (2000???) Hepatic microsomal and peroxisomal docosahexaenoate biosynthesis during piglet development. Lipids 35, 1325-1333.

Ministry of Agriculture, Fisheries and Food (1997) Dietary Intake of Iodine and Fatty Acids. Food Information Surveillance Sheet no. 127. London: Ministry of Agriculture, Fisheries and Food.

Neuringer M, Connor WE, Van Petten C \& Barsrad L (1984) Dietary omega-3 fatty acid deficiency and visual loss in infant rhesus monkeys. Journal of Clinical Investigation 73, $272-276$.

Otto SJ, van Houwelingen AC, Manninen A, Godfrey K, LopezJaramillo P \& Hornstra G (1997) Maternal and neonatal essential fatty acid status in phospholipids: an international comparative study. European Journal of Clinical Nutrition 51, 232-242.

Ottosson UB, Lagrelius A, Rosing U \& von Schoultz B (1984) Relative fatty acid composition of lecithin during postmenopausal replacement therapy - a comparison between ethynyl estradiol and estradiol valerate. Gynecology and Obstetric Investigation 18, 296-302.

Postle AD, Al MDM, Burdge GC \& Hornstra G (1995???) The composition of individual molecular species of plasma phosphatidylcholine in human pregnancy. Early Human Development 43, 47-58.

Salem N, Powlosky R, Wegher B \& Hibbeln J (1999) In vivo conversion of linoleic acid to arachidonic acid in human adults. Prostaglandins, Leukotrienes and Essential Fatty Acids 60, 407-410.

Silfverstolpe G, Johnson P, Samsice G, Svanborg A \& Gustafson A (1981) Effects induced by two different estrogens on serum 
individual phospholipids and serum lecithin fatty acid composition. Hormone and Metabolic Research 13, 141-145.

Sprecher H (2000) Metabolism of highly unsaturated $n-3$ and $n-6$ fatty acids. Biochimica et Biophysica Acta 1486, 219-231.

Su HM, Bernardo L, Mirmiran M, Ma XH, Corso TN, Nathanielsz PW \& Brenna JT (1999a) Bioequivalence of dietary alpha-linolenic and docosahexaenoic acids as sources of docosahexaenoate accretion in brain and associated organs of neonatal baboons. Pediatric Research 45, 87-93.

Su HM, Bernardo L, Mirmiran M, Ma XH, Nathanielsz PW \& Brenna JT (1999b) Dietary 18:3n-3 and 22:6n-3 as sources of 22:6n-3 accretion in neonatal baboon brain and associated organs. Lipids 34, Suppl., S347-S350.

Toth MJ, Gardner AW, Arciero PJ, Calles-Escandon J \& Poehlman ET (1998) Gender differences in fat oxidation and sympathetic nervous system activity during submaximal exercise in older individuals. Clinical Science 95, 59-66.

Vermunt SHF, Mensink RP, Simonis AMG \& Hornstra G (2000) Effects of dietary $\alpha$-linolenic acid on the conversion and oxidation of $\left[{ }^{13} \mathrm{C}\right]-\alpha$-linolenic acid. Lipids 35, 137-142.

Voss A, Reinhart M, Sankarappa S \& Sprecher H (1991) The metabolism of 7,10,13,16,19-docosapentaenoic acid to $4,7,10,13,16,19$-docosahexaenoic acid in rat liver is independent of a 4-desaturase. Journal of Biological Chemistry 266, 19995-20000.

Watkins JB, Klein PD, Schoeller DA, Kirschner BS, Park R \& Perman JA (1982) Diagnosis and differentiation of fat malabsorption in children using $\left[{ }^{13} \mathrm{C}\right]$-labelled lipids: trioctanoin, triolein and palmitic acid breath tests. Gastroenterology 82, 911-917. 